\title{
Bodies and everyday practices in designed urban environments
}

\author{
Monica Degen, Gillian Rose and Begum Basdas
}

\begin{abstract}
In recent years, the centres of many towns and cities have been reshaped by urban design projects, but little attention has been paid to how these transformations are experienced everyday by users of the city. In other words: how do the users of urban centers, such as shoppers, cleaners, or workers, perceive these changes, as embodied subjects in specific material environments? This paper analyses how bodies in two intensely designed urban spaces-the shopping centre of Milton Keynes, a 1960s new town, and Bedford's recently redeveloped historic town centre-are affected by elements of the built environment. 'Affected' is a term borrowed from Latour (2004), and the paper works with, and elaborates, some of his and others' work on how bodies are effectuated by other entities. Such Latourian work pays a great deal of attention to how bodies are affected by both human and non-human entities of many kinds, and we examine how certain aspects of the built environment in these two towns affect bodies in specific ways. However, we also emphasise the variability in this process, in particular that bodies seem unaware-or ambivalently aware-of many entities' affordances.
\end{abstract}

Keywords: experience; urban design; embodiment; ANT

\section{The urban in Science and Technology Studies}

Walking down the high-street to get a sandwich in our lunch break, we notice a change in the floor texture and glance down: a new pavement design has been recently introduced. Waiting for friends by the benches near McDonalds, we are aware of, but do not listen to, the repetitive jingles from the shopping mall's PA system. Taking the children with us while we are shopping, we take a look at a pair of red shoes in a shop-window while we keep an eye on our child. These are just some of the mundane things that happen in contemporary urban spaces.
These moments are made possible by specific conjunctions of experiential corporealities and material surroundings. The physicality of the city constantly interacts, supports and collides with our bodies. And our bodies respond to, go along with, or ignore these environmental affordances. In other words, our experience of built environments is constituted through the foldings of flesh and stone (Sennett, 1994).

That the design of urban spaces can affect people's experiences of them, and even behaviour within them, is a claim with significant contemporary resonance. As Lonsway (2009) has recently argued, it is a claim that underpins many of 
the professions concerned with urban design, and has become increasingly important as efforts to build the "experience economy" have grown. In tracking the emergence of this claim, Lonsway (2009) points to the confluence of cognitive environmental psychology and quantified spatial semiotics, as well as the commercial take-up of versions of the work of Kevin Lynch, Christian NorbergSchultz and Christopher Alexander, in the development of "the perception of space as a system, discretely controllable through pattern templates, under the control of the dominant narratives of a universal language" (Lonsway, 2009: 66). In this broad school of thought, 'experience' is reduced to the perception of specific visual and spatial elements in the designed environment, and human experience becomes the direct result of those elements. And there are other, significant historical precedents to the notion that the built environment shapes human perception, of course. Disciplines such as architecture (see for example Bloomer and Moore, 1977; Le Corbusier, 1931; Rasmussen, 1962; Mikellides, 1980), social theory (Simmel 1971, 1997; Benjamin, 1997; Foucault, 1977, 1980; or more recently Pile 1996; Howes 2005), and environmental psychology (for example Gibson 1986; Lynch 1960), as well as philosophical schools such as phenomenology (see Merleau Ponty, 1969; Bachelard, 1992), have all discussed from different ontological positions the relationship between perception and the built environment. Underlying all these discussions, in different ways, is the assumption that particular effects are inscribed in the physical texture, design and landscaping of these spaces, and that these effects control, order and manage how people experience their surroundings (Dovey, 1999).
It is outside the scope of this article to engage with these various approaches in depth. Instead, we wish to contribute to one of the most nuanced of recent attempts to find a way of discussing how physical texture and lived bodily experience affect each other, namely Actor Network Theory (ANT). As Latour insists "the distinctions between humans and nonhumans[... are less interesting that [sic] the complete chain along which competencies and actions are distributed" (Latour 1992: 243). Yet neither ANT, nor the wider field of Science and Technology Studies (STS), have paid a great deal of attention to bodies in cities (Hommels, 2005; Coutard and Guy, 2007), and this gives us opportunity, in turn, to refine both how urban studies as well as ANT address the topic. STS on urban environments have largely focused on researching technological infrastructures such as electricity and waste networks, or have examined how the urban landscape has been inscribed with meanings and ideologies by the producers of cities: planners, architects or designers (see Aibar and Bijker, 1997; Brain, 1994; Woodhouse and Patton, 2004; Moore and Karvonen, 2008). There has been a notable lack of empiricallygrounded discussions of the production of 'users'-human or otherwise-of urban technologies, whether in the context of architecture or CCTV technologies (see also Coutard and Guy, 2007; Yaneva and Guy, 2008). All this has led Hommels to contend that, "rather than being the focus, the city functions as a mere locus in this research" (2005:325). In neglecting the agency of humans in this way, STS is echoing a similar uninterest in the large literature devoted to critically examining the redevelopment of western cities in post-industrial times (see for example Harvey, 1989; Sorkin, 1992; Zukin, 1995; 
Sassen, 1994; O'Connor and Wynne, 1996; Hall and Hubbard, 1998). Large-scale planning interventions in urban spaces in the form of regeneration projects have become more commonplace across the globe, but the literature devoted to them has also been reluctant to analyse what sort of embodied human-ness is thus created (Callon and Rabeharisoa 2004), preferring instead to analyse how global economic processes shape and change the physical landscape. The analytic focus is at the level of the nation state or the city or the neighbourhood, and routinely ignores the body (for a critique see Nielsen and Simonsen, 2003; Masuda and Crooks, 2007). Yet, just as studies on design technologies greatly benefited from researching how end users make sense of these technologies, because both the users and the design are "completed in the consumption of these technologies" (Crosby, 2004 quoted in Coutard and Guy, 2007:724; see also Cowan 1987; Williams et al. 2005; Berger et al. 2006; Sorensen 2002), so too would studies of bodies and urban form.

There are signs, though, that this neglect may be on the wane in urban studies. In relation to analyses of lived experience influenced by Actor Network Theory, a range of commentators have recently acknowledge that ANT-informed studies of the "'effectivity of (quasi) objects' has too often forgotten the 'affectivity of (body) subjects'” (Whatmore 2002:161 quoted in Anderson 2004:743), and have emphasized the need to research how the experiential fabric is configured not only through materials but also in relation to "corporeal configurations of energies" (see Whatmore, 2002:36; Anderson, 2004; Bissell, 2007).

How to think about the ways in which everyday embodied life in the city becomes "a field of movements; a swirl of forces and intensities which traverse and bring into relation all kind of actors, human and non-human, in all manner of combinations and agency" (Amin and Thrift, 2002:83)? This paper draws on the work of Latour and others, as well as empirical work on everyday practices in two extensively designed urban spaces: the shopping centre of Milton Keynes, a 1960s new town, and Bedford, an historic town whose centre has been redeveloped in various ways since the $1980 \mathrm{~s}$, to explore how the design of the material environment and people's embodiment co-constitute the experience of these two particular places. The following section explores that co-constitution in more theoretical terms, drawing in particular on Latour's (2004) concept of the body as an "interface" that is effectuated in its encounters with urban entities. The next section discusses some of the methodological aspects of our study, and the paper then elaborates a range of rather distinct performances of that interface. In the last section, we discuss the implications that our findings have for understanding sensing bodies in cities.

\section{Latourian approaches to experience in the city}

Issues of embodiment are crucial in understanding what transpires in chains of competencies and actions, but Latour himself only explicitly focuses on the body in a restricted number of essays. A key statement is of course his essay 'How to talk about the body?', in which he argues that "to have a body is to learn to be affected, meaning 'effectuated', moved, put into motion by other entities, humans or non-humans" (Latour 2004: 205; and see Hennion 2007). A specific example he uses to make this point is the training of people to work in the perfume industry, in which bodies learn to 
discriminate odours as noses gets trained to smell and distinguish between an evermore-subtle range of fragrances. Bodies, Latour concludes, meaning sensory perceptions, constantly transform through engagements with other entities, whether human or non-human.

Latour makes the same point in relation to a range of different entities in urban spaces in his web photo-essay account of urban life, 'Paris: invisible city' (Latour 2006). The essay works with interactive images and words to create a 'sociological opera', exploring how Paris is only made possible through the interplay of various technological systems, objects, institutions, rules and human inhabitants. Latour guides us through the city gradually tracing and thereby disclosing the hidden infrastructures and institutions of traffic control, way-finding, water services and so on that allow the running of urban life. What interests us in this account is his diverse sensory experiences of the urban environment: "I'm not simply passing through Paris: the 'I' also passes through forms of action, regimes of intelligence that are virtually unrelated to one another. In front of the bank automat I had to act as a generic being endowed only with an individual pin code; pressed against the barrier on the pavement I was a mechanical force weighing against other mechanical force" (Latour 2006:67). Here we have an account of the body that stresses its malleability, as it responds, interacts and reshapes itself according to the affordances of its surrounding entities.

One can identify some commonalities with Deleuzian approaches to embodiment here, where "corporeal perception and sensation is thus an incorporation of matter in the connective tissues and affective planes of the body subject whose ambit is involvement and engagement, rather than detached gaze in which materiality stiffens into objectivity" (Anderson and Wylie 2008:7; see also Lorimer 2008; Verbeek 2005), which for Amin and Thrift (2004: 84) means "to see the city as a kind of force-field" where agency is distributed amongst various entities, including bodies and buildings (see also Amin 2008). In this theoretical moment, it is through paying attention to embodied practices, meaning kinaesthetic-sensory engagements that we can start to understand the unstable and complex entanglements configured through the constant re-assemblage of entities and corporeal intensities. However, ANT studies working with notions of the bodily tend to emphasize the agency of urban technological entities more than Deleuzian approaches. It is crucial to Latour's argument that the 'fragrance kit' with its multiple odours becomes "coextensive with the body" (Latour 2004:207) as it is this kit that allows for and trains bodies progressively to identify a variety of sensations. Here, the body acts as an interface that "leaves a dynamic trajectory by which we learn to register and become sensitive to what the world is made of" (Latour, 2004:206). The body is conceived as a process, rather than a fixed substance; "it involves an important shift from relational 'being' to relational 'becoming'" (Whatmore 2004:161). ANT writers on the body, while by no means adhering to a unitary theoretical position, share this tendency to pay attention to the way specific sorts of bodies are created in collaboration with other things-medical technologies, discourses, animals, for example (Akrich and Pasveer 2004; Berg and Akrich 2004; Berg and Mol 1998; Callon and Rabeharisoa 2004; Lorimer 2008; Mol 2002)-such that the body becomes "the empirical result of practices" with those various things (Berg and Akrich 2004: 3). 
There is no doubt that this argument produces rich insights into the productivity of technologies and discourses, and does crucial work in displacing humanistic accounts of agency. However, this paper explores a question begged by Latour's account of being affected-or to use another of his terms, 'formatted'- in urban space: "from one second to the next," Latour writes, "different regimes of action are relayed to one another, leading me from one competence to the next. I'm neither in control nor without control: I'm formatted. I'm afforded possibilities for my existence, based on teeming devices scattered throughout the city. I go from one offer to the next" (2006:68). The question this poses for us, and which this paper explores, is: are all those offers equally pressing?

Latour suggests not: "nothing in a given scene can prevent the inscribed reader or user from behaving differently from what was expected... The user of the traffic light may well cross on the red" (1992: 237). However, not a great deal of attention has been paid in ANT studies to the variability of entities' offers to format the body (though see Hyysalo 2007). This paper suggests that, in the urban environments of two rather ordinary towns, variability is crucial to take into account when exploring the coconstitution of bodies and entities. In the remainder of this paper, then, we provide an empirical investigation of Latour's arguments by following a range of people through their routine uses of two city centres. If by focusing "on the body, one is immediately-or rather mediatelydirected to what the body has become aware of" (Latour 2004:206), we suggest on the basis of these trips that while the body is aware of diverse aspects of the material environment, the nature of this awareness is highly variable; moreover, it can work to mediate entities' 'offers' which are thus not always as powerful as Latour's writings tend to imply.

\section{Researching urban experience in Milton Keynes and Bedford}

Before proceeding further, we would like to reflect briefly on the towns researched and the methodology of this study. Milton Keynes is a 'new town', conceived in late 1960s and built in large part in the following two decades. Central Milton Keynes is a large, low-density city centre. It is characterized by a grid structure, modernist urban design and architecture, parking lots, and extensive open spaces. Its largest building, now called thecentre:MK (hereafter CMK), was built in the 1970s as a covered high street, open to its surroundings and including a large space inside for communal events. The building's private owners, however, very quickly turned it into something much closer to a shopping mall than a public high street, with doors, opening hours, and security guards on patrol. The centre was extended at its western end by another shopping building in 2000 . Both the old and new parts are high quality design; both are privately owned, although any external changes to their design require agreement from planning authorities.

Bedford, in contrast, is an old market town. Its architecture reflects a mixture of styles from Victorian brick and plaster, turn of the century art-deco, white and black mock-tudor, and concrete 1960s developments. Its town centre was pedestrianised in the 1980s. More recently, reflecting Britain's urban regeneration trends, its town centre has undergone an environmental improvement scheme which has included raised flowerbeds, 
a small sculpture playground for children, a number of sculptural play installations and some newly designed street furniture. The redevelopment was funded by the local council, and is also supported by BedfordBID (Bedford Business Improvement District), who contribute to the regeneration practices by marketing the town centre, improving its businesses, and making it a safe space. BedfordBID introduced the 'bluecaps,' who patrol the town center, ensure security, and provide local information.

We started our eighteen-month research project into Bedford's town centre and Milton Keynes' shopping centre with three months of participant ethnographic and photographic observation. The aim was to record the 'doing' of these town centres, in terms of who was using these spaces and how they were using them by focusing on bodily comportments and gestures, but also exploring the 'feel' of each town centre. Thus, we observed the spatial layout of each place, its physical landscape and the daily and weekly shifts in the town centres' routines and rhythms. Lastly, we observed our own embodied experiences in these designed spaces. The latter method was particularly important in regards to tracing and sensing the agency and interventions of the urban fabric on our bodies. Our own bodies in this instance became the sensory vehicles to chart the various relational engagements between bodies and design environments, and helped us to trace the moments in which particular experiences were composed in particular interactions between humans and non-humans in the shopping mall or highstreet. An example is the attraction of a musical chime on the floor of the high-street in Bedford. While we observed both children and adults jumping with delight on these chimes, it was only when doing it ourselves that we started to acknowledge the importance of sensing with the object as an embodied and 'formatted' experience.

To assess whether the predominant practices we observed produced different experiences of these spaces, we followed the ethnographic observation with a large-scale survey asking a total of around 400 people in each town what they were doing in the town centres, whether they liked or disliked the town centre, and how they would describe it in three words. The aim was to explore relations between the practices that people were doing with their experience of the environment.

What quickly emerged from both of these methods is that people were pursuing all kinds of activities besides shopping in both places. Our large scale survey found that less than two-thirds of people described their main activity as shopping $(62 \%$ in $\mathrm{CMK}$ and $57 \%$ in Bedford). Other activities described included socialising, working or enjoying a day out. As a result of our ethnographic work and the survey, we identified four significant practices. Firstly, shopping; this needs to be divided into taskoriented shopping and browsing around the shops. Secondly, caring which broadly refers to looking after children or older people while using the city centre. Thirdly, socialising. People rest on the benches, meet acquaintances and watch the world go by, and teenagers congregate in certain areas of the town centers. The fourth important practice we identified is maintaining, which refers to various activities by security officers and cleaners, and includes surveillance, cleaning and generally ensuring the smooth running of the main public areas used. What these findings reveal is the way in which particular practices pull together certain co-operations between bodies 
and entities that produce distinctive embodied experiences (see also Frers and Meier 2007). To understand what happens more carefully, we also wanted to pay closer attention to the multiple modes of action and inaction that emerge in the interactions between bodies and things, which the next method offered.

To access the immediate experience and 'doing' of urban space, we adapted Kusenbach's (2003) method of the go-along, in which the researcher accompanies an individual on an everyday journey. We accompanied 25 individuals (sometimes with family and friends) around the two town centres on what we call 'walk-alongs', as they pursued their routine everyday tasks, from walking with individuals during their lunch break, to leisurely browsing for clothes or hurriedly buying a gift. The walk-alongs lasted from 45 minutes to several hours. We recorded our conversations and where we went, what we did, and observed how they moved and used their bodies; we also asked our participants to take photographs of things that particularly struck them on our walk, and we used these photographs as a basis for a follow-up interview in which they reflected on the walk and on the town centres more generally. Such a method permits examination of the interactions that arise between physical and human actants in situ and as they emerge. Our aim in these walk-alongs was to get closer to the unspoken, embodied relational engagements that produce experiences of the urban. Our participation in these walks facilitated new levels of awareness of the diverse sensory modalities of engagement and uses of space. They allowed us to chart the multiple and various ways in which the potentialities of the environment are realised by different bodies moving through and sensing the two town centres. While our presence certainly affected these individuals' experiences in some ways, it did also allow us to engage, if only partially, other people's experiential world and then to consider this experience reflexively (see also Pink 2008).

\section{Everyday practices in designed urban centres}

Our fieldwork has produced a rich account of people doing all kinds of things in and with Milton Keynes and Bedford town centres. Indeed, what people do in these town centres is central to our understanding of their experiencing of those spaces. We agree with Latour's (2004; 2005; 2006) assertions that the body and the surrounding material environment are in permanent flux, constantly folding and unfolding; and, that the body digests, adapts and transforms in relation to the potentialities offered by its surrounding environment. But our research has also highlighted a more nuanced inflection of bodies and urban entities. Let us explain.

So far, we have argued that urban experience is distributed and formed in and through entanglements of human and non-human entities. In Amin's words: "technology, things, infrastructure, matter in general should be seen as intrinsic elements of human being, part and parcel of the urban 'social', rather than as a domain apart with negligible or extrinsic influence on the modes of being human" (2008:8). Amin (2008) further views the rhythms of daily life in urban spaces as a 'collective response' that arises out of a 'situated spatial practice'. Implicit in this argument is the suggestion that places can generate collective experiences. It is the practices or activities that individuals are involved in that override their subjectivities in the experience of designed urban environments. In contrast to much work in the social 
sciences, this suggests that bodily sensing and corporeal comportment are inflected by and embedded in the particular practices that bodies are undertaking, rather than individual subjectivities linked to age, gender, class or race. Indeed as Frers (2007) argues, perception and practice should not be regarded as separate but informing each other. Perception is shaped in relation to the particular practice one is engaged in. The particular activities that our body (and mind) are involved in, inform our perceptual sensibilities and shape both the perceived environment and our bodily dispositions. Dant similarly suggests that "[the] communication process between humans and objects is 'pragmatic' in the sense that meaning is contingent on the current situation that continually unfolds in the course of the interaction with the object"(2008:15). Here we are moving away slightly from the Latourian emphasis on the production of bodies by offers from other entities, and towards a greater emphasis on the effects of practices: that is, how entities are brought together. Let us clarify this move by looking in more depth at some of the practices we identified from our ethnographic observations and large scale survey: maintaining, shopping, socialising and caring. Before we start, however, it is important to note that while for clarity we have separated these practices in the discussion that follows, actually they often occur in succession or even alongside each other.

The practice most in tune with Latour's (2006) description of how the various infrastructures, technologies, things and activities configure and make possible the embodied experience of Paris, is what we identified as the practice of maintaining. Most of the times invisible to most of the users of the city centre are an array of entities, including people, institutions and technologies, that, as they are brought together, help to stabilise the city as an artefact and thereby simultaneously shape the experiences afforded, as discussed in depth by Latour. What our research has highlighted, though, is that, for private security officers, cleaners and bluecaps, the built city centre and its users are experienced very much a 'social whole' that needs to be repaired, cleansed or controlled. So, for example a walkalong during a routine walk with one of the bluecap security guards around Bedford, exposed how the activity of 'maintenance' directs the security guard's attention in particular ways as she is enrolled into a multiplicity of actions and diverse actors, from human small chats with people to CCTV circuits:

"During this trip we stopped by a few local shops for small chats and hear about shop-owners' needs. We helped an old lady find local sports uniforms for her grandkids in the United States. We reported some of the shops that had closing down signs on their windows. And, we observed the cameras in the CCTV security office where the bluecaps were asked to watch a young girl 'suspiciously' strolling the streets. Shannon and her colleagues do this routine everyday, assuring the maintenance of the town center in collaboration with the businesses and the police." (Begum, walk-along notes, Bedford, 20 June 2008)

During her patrols of the city centre Shannon's sensory perceptions are on constant high alert focused on surveilling, repairing, helping, and so on. Sharon's body is attentive to any possible incongruence in the urban landscape. During the walk-along she kept focusing her eyes on details in the environment such as checking out people: sometimes 
greeting, sometimes giving directions, other times following 'suspicious individuals'; benches: benches that had gone, benches that were broken, benches that needed re-painting; rubbish: have rubbish bins been emptied regularly, picking up cans; cars and lorries: directing traffic, giving instructions, and so on. The environment and its users become amalgamated as a hybrid functional entity that needs to be kept in order and effectively running.

Another practice we identified in both towns was task-oriented shopping, which involves searching for a specific commodity or completing a chore. Here, the way in which a particular practice can modify the 'offer' of particular entities by reducing bodily awareness of them became clearer. During this practice bodies tend to walk purposefully, quickly, with the head either down or gazing straight ahead; the eyes do not focus in detail on the immediate surroundings but concentrate instead on navigating the space to the required destination. Women are often walking fast clutching their bags, men can be observed focusing on a shopping list. This is a gaze that pays attention more to material spatial arrangements than to visual delights: straight here, left here, usually respecting the dominant movement pattern of other bodies, however, although often frustrated at its slow pace. In Central Milton Keynes, the design of the mall building activates the stream-lined movement of bodies, and thus the movement is highly normalised with people walking in more-or-less straight lines up and down the avenues: "It kind of forces people to do this back and forth walking thing, and you end up forming sort of streams of traffic" (Susan, follow-up interview, CMK). Perception in this practice is relegated to scanning visually the environment. The physical surroundings become a perceptual backdrop. Shops, people, objects that do not form part of the task are simply ignored and fall out of the perceptual radar. The affordances of space aid mobility, yet little else.

Another example of the same selective awareness occurred during our walkalong with Tim, an urban designer for MK council, when he did not recognize two public art features, a tower clock and bronze chimes, on his way as we walk fast during his lunch break (Tim, walk along notes, CMK). Since Tim does not comment on them, Begum asks what he thinks of the bronze chimes. Tim says, "I've never seen it before. I might have before, but obviously it has not been memorable." Begum then further asks about the tall clock tower right in the middle of the shopping aisle. Tim responds, looking back and forth, "Where? Is there a clock?" He rushes through the shopping centre to get what he needs to get done, such as getting a gift for his wife or returning a book to WH Smith. He remarks on the beauty of the perspective on the long aisles but he does not perceive the bits and pieces on the aisles. His behaviour displays a scanning modality of attention. These findings contradict some of Latour's (2004) assumptions that as the body engages repeatedly with the world it keeps 'learning to be affected'. Instead we can see how both the increased familiarity with an environment and the need to focus on a specific task can lead to the blending out of, and selective attention to, specific entities.

Another practice often linked to shopping-waiting/resting-reveals a different assemblage of perceptual sensibilities, materialities and bodies. Here, bodies start slowing down and scanning the environment for objects that afford slouched or relaxed bodily comportments: benches, chairs, walls, and raised floors. 
"The girl was talking on the phone by the Post Office, she had a few bags in her hand. Then, she met with another woman; with them so many bags and they squeezed into the little bench together-across from the Poundland. They kept talking to each other. They were looking ahead, but they seemed rather blank. They did not look like they are seeing what they were looking at." (Begum, ethnographic notes, Bedford, 11 December 2007)

Bissell (2008) has recently written about the complex configurations of comfort that shape and produce the sedentary body. One of his central arguments is that experiences such as comfort do imply the co-operation between bodies and objects which produce various forms of feeling and resonances with the environment. In his words, this creates an "affective sensibility", yet one that needs to be constantly re-negotiated (2008:1707). Similarly, the practice of waiting involves constant re-adjustment of bodily comportments to the physical environment such as leaning against a wall and staring blankly into the distance, or spreading one's legs while trying to fit one's body shape to the curvature of the bench. It is further composed through particular material practices such as fidgeting with a bag, checking the mobile phone, holding a drink while chatting to the person next to us, reading a shopping list, feeding a baby.

"A lot of the people with their backs turned to shops, facing the aisles pause by these surfaces, lean their backs to the shop windows or the walls between them to rest from walking, to talk on the phone, wait for the friend to come out from the store, or to talk to each other." (Begum, CMK ethnographic notes, 8 December 2008)
What we are confirming here is that experience is not an individual or subjective state of mind, nor simply an act of perception, but that many entities become part of, and aid, moments of embodied experience. Experiences are thus not only situated in specific moments of time and space but are also underpinned by particular bodily dispositions and objects. As Michael suggests: "space, here, emerges from such mutual performativities (or warpings) enacted by persons-and-theirartefacts interacting with persons-andtheir-artefacts" (2006:116). Thus personartefact relations are not only between the person and their artefact, but can also produce relations between other people and their artefacts. A mobile phone becomes not only a communication device but also a privacy screen as bodies turn away in a personal conversation; plastic bags are not just carrying devices but act as barriers to protect one's personal space when sitting down. Again, we want to push Latour's argument a little further than he does by emphasising the variability of entities' offers and the formatting that they do. Not only do entities offer embodied possibilities, but the same object can be utilised in quite different ways, depending on the practice in which it is involved.

When socialising, i.e. walking with and talking to a friend or family member, or talking to someone on a mobile phone, another type of perceptual configuration emerges. Individual's perceptual attention is very much focused on the other person or the subject matter. Their heads half turned towards each other while talking, focusing one's hearing to capture the words, reading bodily cues, scanning with the edge of their eyes what's ahead, and blending out much of the spatial background sensations. All surroundings therefore often get blanked 
out or ignored. For example, on one of our walk-alongs Susan was going to the post-office to send off her Christmas parcels. Begum notes on her walk-along with Susan:

"We keep talking about her family and how she strategizes about sending the parcels as one pack or in groups. She keeps talking fast giving me all this information about how much she needs to get things sent and how she is behind on this. ...During her talks, I realized we passed the Post Office. I paused and asked her if we passed the Post Office. She was not sure. We looked back and forth trying to figure it out. Then she approached the map to look where the post office is located and commented on how often she gets lost." (Begum, walk-along notes, CMK, 12 July 2008)

In this instance, Susan was so immersed in sharing her thoughts with Begum that she completely lost track of where she was going. Such behaviour stands in contrast to the importance of accurate way finding in task-oriented shopping. Indeed, what we observe here is how these different experiential constellations can intersect and even disrupt each other. Susan's trip was task-oriented because she needed to post her parcels, but her absorption in the sociable "envelope" (Frers and Meier 2007) between her and the researcher caused her to forget to scan the environment, and she got disorientated. Here we can see very clearly how different kinds of bodily awareness are created by specific practices.

Another modality of socializing occurs when teenagers are hanging out with each other in the town centre. This also entails diverse sensory engagements with the environment. Teenagers establish quite distinct sets of relationships to each other, the environment, and other people outside their group. Their bodily dispositions are more playful and flexible, but yet tentative, responding to and negotiating with the environment as the below walk-along excerpt notes:

"As Angie and Emily move around the center their bodies are not these stiff bodies that move up and down. They are more open to registering and responding to different stimuli. They sing, dance, make small silly moves, and engage with each other. However, they also pay attention to anything that has some kind of "play" aspect. They were talking about one temporary stand in the center by McDonalds, where one could sit on some giant sofas and spend time. Angie really enjoyed this recalling, "It was amazing!". When we were by John Lewis they noticed a man inside the window display ironing things with a big ironing board. They were quite intrigued and entertained by this, waving and smiling at him, by using signs asking him if they could take a photo of him and they did. They had so much fun." (Begum, walk-along notes, CMK, 4 September 2008)

For these two girls, the shopping center is transformed into a place of laughter, memories, and intimate friendships. The material environment is a richly textured playscape that they respond to and engage with. The teenagers' attitudes to the environment transform the mall into a space of fun possibilities. However, these two teenagers also had a rather different awareness of the mall, related to their interest in the social aspects of the center. As well as a space to play in, these young women also use the mall as a way of finding their friends and checking out other people, mainly other teenagers. As we walked-along with them, they talked 
about the areas in the mall which they had once used as spaces in which to hang out with their mates, but from which they had now been banned. The mall's security guards no longer allowed young people to gather in an outside square accessed from inside the mall; they were also moved on if more than three or four gathered in a group outside a fast food outlet in the mall. Here the mall was thus also felt as a place of exclusion, its geography mapped by the im/possibility of just hanging out. For these teenagers then, the mall as a hang-out is constituted as both an environment for play and as forbidden spaces. This is another clear example of the "reversibility of energies between bodies and worlds" (Whatmore 2002:5), in which practices produce not only specific embodiments but also specific built environments. We can also see how a particular practice-hanging out-can entail two quite different perceptions of the mall: one "so much fun", in which anything can become a resource for play, and the other a highly policed environment in which "we had our shopping bags. And he came to kick us out. It was like OMG!" (Angie, walk along, CMK). Here, the constitution of these young women and CMK is multilayered, a complexity of offering that Latour's writings do not emphasise.

A different assemblage of the bodypractice-environment relationship is produced when engaged in caring while using the city centre. In this practice, the bodily pace is slowed down and adjusted to the other person's ways of experiencing space. Caring for or looking after somebody else-usually an elderly relative or children-means readjusting one's awareness in order to experience environmental affordances from another perspective. 'Envelopes' thus become more focussed and more linked to another person. During the follow up interview,
Jennifer commented on her walk-along experience with her two young children in Milton Keynes shopping center:

"It's a bit like when you're driving a car and that you have to pay attention to what you're doing and what the other driver's doing around on the road, and all that kind of stuff, but when you've then got the children in tow you have two more cars that you're controlling but with independent thought and you have to think about your surroundings, and you have to think about the shop surroundings and the other people, so a way of doing that is to hold hands, and have them at all times, but you also have to still concentrate on physically where you're walking. Can you and the person you're holding hands with navigate the space? Are the other person's hands reaching onto things they shouldn't be touching? You also have to concentrate on what you want to buy, what the other child is saying about the environment, and then other people on top..." (Jennifer, CMK follow up interview)

When two friends are engaged in shopping and socializing at the same time, their perception tends to be arranged in the form of the perceptual 'envelopes', as we have already noted. When engaged in caring, however, those envelopes are structured by the characteristics of those being cared for; they become more intense as a result, more like bubbles. Although Jennifer acknowledges the children's independency, she assures that they never take off. They walk all together like a big convoy of bubbles across the shopping center. Once again, we can see from these examples that being affected by a material environment is not a consistent process; attention given to other things (children, the shopping 
task) can create a minimal relation to the surrounding materialities.

In a different example of caring, this time in Bedford town center, experiences of frustration and physical endurance emerge in the relationships between the mother, practice of pushing the pram, and the form and texture of the physical environment. While Louise is pushing the pram, her baby Lucy sits in there, and the pram becomes a heavy extension of Louise's body. Any obstacle that the pram has to overcome to keep moving is felt by Louise, who carefully manoeuvres and pushes the pram with all her strength. As the below excerpt suggests, Louise's environmental perception is mediated by the pram's ability to move and cope through the spaces. Like the perfume expert in Latour's writings who " $[\mathrm{t}] \mathrm{hrough}$ the training sessions, [...] learned to have a nose that allowed her to inhabit a (richly differentiated odoriferous) world" (2004:207), Louise's sensitive body has learned to inhabit a richly differentiated spatio-material world informed by the mobility of her pram:

“Louise's engagements with the physical environment resemble a game where different textures and obstacles continually appear to challenge her movements forward. Pushing the heavy pram with the baby, as the groceries hang behind the pram, is a nightmare for her on the cobblestones by the market. She complains about the café in the piazza for further crowding the place. She is really pissed off about the trash bin located in the middle that she circles the pram around. She noted that eventually she found an alternative route that passes through the church to get to the market to avoid all that effort. Her relationship to stores in the town centre is determined by whether they have automatic doors to enter, sufficient interior space to circulate, or toilettes to change baby's diapers. Although she likes her Saturday family outing in the town center, she defines it as a struggle.” (Begum, walk-along notes, Bedford, 11 October 2008)

CMK on the other hand, was designed with wheelchair users in mind, and thus none of our research participants with pushchairs faced anything like Louise's efforts to make the built environment more convenient for her needs. During Louise's walk-along, caring did also include those bubble-like periods of intense focus, but it involved other sensory engagements, more concerned with the physical navigability of the town centre, too: layout, surface texture, obstacles. And here we return to a co-constitution of body and entitieselements of the built environment-that is closer to Latour's account of bodies being affected by entities.

What all these examples illustrate is the variable relationships between entities in urban space. We have focussed specifically on relations between human bodies and the 'offers' made to them by elements of the built environment, and have argued that bodies' awareness of such elements is guided by particular practices which produce diverse kinds of awareness. Surveillance, scanning, bubbles, struggle, sitting, absorption, envelopes, play: all of these are somewhat different assemblages of senses, entities and bodies, variously constituted by specific practices. Sometimes the environment becomes a close-up area where you perceive things clearly, and a more blurred wider perception, which might screen perceptions out or selectively present them; sometimes a more extensive gaze, charting a route for speed or accessibility. Sometimes the physical layout is barely registered, 
at other times it becomes an obstacle course. Sometimes those assemblages are consistent, at other times they are ruptured as ambivalent. However, these possibilities are not static, they fold in and out. As bodies move across environments and we negotiate our way with surrounding human and non-human entities, different bodily and architectural offers momentarily crystallise, only to disintegrate and reform again. The slipping between different practices and their associated perceptual fields that we have described often occurs within short time spans, often a few minutes. On the one hand, this produces a rich sensory texture when focused on in detail. We describe this variability as 'differentiated awareness'.

We suggest the notion of 'differentiated awareness' can capture this material, mobile process whereby different forms of embodied experiences fluctuate through multiple intensities of interaction with the material environment. We also suggest that these intensities are indeed multiple; they are of different kinds, and can be multilayered.

\section{Conclusion}

It is clear from our research that the many and various ways in which ordinary practices are done in town centres creates a wide range of engagements with the affordances of the built environment. In a slight change of emphasis from some of Latour's writing, though, we have emphasised the specific practices through which bodies and materialities become assembled in particular spaces. Such practices configure embodied awareness in particular ways, and that awareness then mediates the 'offers' made by elements of the built environment; practice here is the "switch-point" between the bodily and its relation with human and non-human entities (Blackman 2007: 18). We have emphasised the diversity and richness of such awarenesses, and the different ways in which bodies are effectuated, hence rearticulating within ANT the concerns that have been previously raised elsewhere (e.g. Lave, 1988; Cole, 1996; Clarke, 2005). Depending on what people are doing, their awareness of, and bodily effectuation with, elements of the built environment can be very different. Not only are bodies multiple, but so too are environments; and not only multiple in the sense of many, but multiple in the sense of ambivalent. It is this sense of multiplicity that the term 'differentiated awareness' refers.

From this research, we want to raise one further point in dialogue with Latourian accounts of urban spaces. Much of our research revealed a very rich sensory engagement with both Bedford town centre and Milton Keynes shopping centre. While our research participants' awareness of the non-human entities in those centres was always quite specific-depending on what they were doing there, as we have argued-they all described, evoked and gestured towards a detailed 'feel' of each place (Rose, Degen and Basdas 2010). However, our project was in part focussed on finding just such sensory engagement: we were interested in how urban design was experienced and felt. What our data also tell us, however, is that most people, in their everyday understandings of the centres, do not articulate their sensitivity to other entities. Our interview material, as well as the large-scale survey we undertook in both town centres, does not suggest conscious reactions to the complexity and diversity of entities in either Milton Keynes or Bedford. Indeed, the modal description in the survey for CMK was "nice" while for Bedford it was "all right": 
neither are terms that suggest strong engagement with the centres. As one of our participants said, nothing says, "Oh come and look at me!". Thus, while this essay has been inspired by Latour's account of bodies/cities in particular, and has sought to elaborate his argument about the effectuation of bodies in urban spaces, it is also clear that the practices highlighted by such an elaboration are far from evoking the "bio-counterpower" that his overall project desires (Latour 2004: 227).

\section{Acknowledgements}

This project was funded by the Economic and Social Research Council, grant number RES-062-23-0223. See also the project website: www.urban-experience. net

\section{References}

Aibar, E. \& Bijker, W. (1997) 'Constructing a City: The Cerdà Plan for the Extension of Barcelona', Science, Technology, and Human Values, 22 (1):3-30.

Akrich, M., \& B. Pasveer (2004) 'Embodiment and disembodiment in childbirth narratives', Body \& Society, 10: 63-84.

Amin, A. (2008) 'Collective culture and urban public space', City, 12 (1):5 -24.

Amin, A. \&Thrift, N. (2002) Cities: Reimagining the Urban (Cambridge: Polity Press).

Anderson, B. (2004) 'Time-stilled spaceslowed: how boredom matters', Geoforum, 35:739-754.

Anderson, B. \& Wylie, J. (2009) 'On geography and materiality', Environment and Planning, 41: $318-335$

Bachelard, G. (1992) The Poetics of Space. Boston: Beacon Press.
Benjamin, W. (1997) 'On some Motifs in Baudelaire', in N. Leach (ed) Rethinking Architecture (London: Routledge).

Berg, M. \& Mol, A. (1998) Differences in Medicine: Unraveling Practices, Techniques, and Bodies (Durham, N.C: Duke University Press).

Berg, M. \& M. Akrich (2004) 'Introduction - Bodies on Trial: Performances and Politics in Medicine and Biology', Body \& Society, 10: 1-12.

Berger, T., M. Hartmann, Y. Punie \& K. J. Ward (eds) 2006. Domestication of Media and Technology (Maidenhead, UK: Open University Press).

Bissell, D. (2008) 'Comfortable bodies: sedentary affects', Environment and Planning A, 40: 1697-1712.

Blackman, L. (2007) 'Psychiatric culture and bodies of resistance', Body \& Society, 13: 1.

Bloomer, K. C. \& Moore, C.W. (1977) Body, Memory and Architecture (New Haven and London: Yale Architecture Press).

Brain, D. (1994) 'Cultural production as 'society in the making': Architecture as an exemplar of the social construction of artefacts', in D. Crane (ed) Sociology of Culture, (Oxford: Blackwell).

Callon, M., \&V. Rabeharisoa (2004) 'Gino's lesson on humanity: genetics, mutual entanglements and the sociologist's role', Economy and Society, 33: 1-27.

Clarke, A. E. (2005) Situational Analysis - Grounded Theory After the Postmodern Turn (Thousand Oaks: Sage).

Cole, M. (1996) Cultural psychology: A once and future discipline (Cambridge: Harvard University Press).

Coutard, O. \& Guy, S. (2007) 'STS and the City: Politics and Practices of Hope', Science, Technology, and Human Values, 32 (6), 713-734.

Cowan, R. S. (1987) 'The Consumption Junction: A proposal for Research Strategies in the Sociology of 
Technology', in W.E. Bijker, T. Hughes \& T. Pinch (eds) The Social Construction of Technological Systems (Cambridge, MA: MIT Press).

Crosby, T. A. (2004) Utilities in Transition: Gazing through the IT window. PhD Dissertation, University of Newcastle.

Degen, M. (2008) Sensing Cities: Regenerating public life in Barcelona and Manchester (Routledge: London).

Foucault, M. (1977) Discipline and Punish: The Birth of the Prison (London: Penguin).

Foucault, M. (1980) Power/Knowledge (Hemel Hempstead: Harvester).

Frers, L. (2007) Einhüllende Materialitäten: Eine Phänomenologie des Wahrnehmens und Handelns an Bahnhöfen und Fährterminals (Bielefeld: Transcript Verlag).

Frers, L. \& L. Meier (2007) 'Encountering Urban Places - Visual and Material Performances in the City', in L. Frers \& L. Meier (eds) Encountering Urban Places: Visual and Material Performances in the City (Aldershot: Ashgate).

Hall, T. \& P. Hubbard (1998) The Entrepreneurial City (Chichester:Wiley).

Harvey, D. (1990) The Condition of Postmodernity (Oxford: Blackwell).

Hennion, A. 2007 'Those things that hold us together: taste and sociology', Cultural Sociology 1 (1):97-114.

Hommels, A. (2005) 'Studying Obduracy in the City: Toward a Productive Fusion between Technology Studies and Urban Studies', Science, Technology and Human Values, 30 (30):323-351.

Hyysalo, S. (2007) Versions of care technology. Human Technology 3 (2):228-247.

Kusenbach, M. (2003) 'Street phenomenology: the go-along as ethnographic research tool', Ethnography, 4:455-485
Latour, B. (1992) 'The sociology of a few mundane artefacts', in W.E. Bijker and J. Law (eds) Shaping Technology/Building Society: Studies in Sociotechnical Change (London: MIT Press).

Latour, B. (2004) 'How to talk about the body? The normative dimension of science studies', Body \& Society, 10: 205-229.

Latour, B. (2004) "How to talk about the body? The Normative Dimension of Science Studies." Body and Society, 10 (2-3):205-229.

Latour, B. (2005) Reassembling the Social: An Introduction to Actor-NetworkTheory. (Oxford: Oxford University Press).

Latour, B. (2006) Paris: invisible city. http:/ / www.bruno-latour.fr/virtual/ index.html, accessed 15.1.2009.

Lave, J. (1988). Cognition in Practice: Mind, Mathematics and Culture in Everyday Life (Cambridge, MA: Cambridge University Press).

Le Corbusier (1931) [1986] Towards a New Architecture (Mineola: Dover Publications).

Lorimer, J. (2008) 'Counting corncrakes: the affective science of the UK corncrake census', Social studies of science, 38: 377.

Lynch, K. (1960) The Image of the City (Cambridge, MA: MIT Press).

Masuda, J. R. \& V. A. Crooks (2007) 'Introduction: (Re)thinking the scales of lived experience', Area, 39 (3):257258.

Merleau-Ponty, M. (1969) The Essential Writings of Merleau-Ponty, in A. Fisher (ed) (New York: Harcourt Brace and World).

Michael, M. (2006) Technoscience and Everyday Life. (Milton Keynes: Open University Press).

Mikellides, B. (1980) Architecture for People (London: Studio Vista). 
Mol, A. (2002) The Body Multiple: Ontology in Medical Practice (Durham, N.C: Duke University Press).

Moore, S. \& A. Karvonen (2008) 'Sustainable Architecture in Context: STS and Design Thinking', Science Studies 21 (1): 29-46.

Nielsen, E. H. \& K. Simonsen (2003) 'Scaling from 'Below': practices, Strategies and Urban Spaces', European Planning Studies 11 (8):911-927.

O'Connor, J. \& D. Wynne (1996) From the Margins to the Centre: Cultural Production and Consumption in the Post-industrial City (Aldershot: Avebury).

Pile, S. (1996) The Body and the City (London:Routledge).

Pink, S. (2008) 'An urban tour', Ethnography 9 (2):175-196.

Rasmussen, S. E. (1962) Experiencing Architecture (Cambridge, MA:MIT Press).

Rose, G., M. Degen, \& B. Basdas (2010) 'More on 'big things': building events and feelings', Transactions of the Institute of British Geographers 35: 334-349.

Sassen, S. (1994) Cities in a World Economy (Thousand Oaks: Pine Forge Press).

Sennett, R. (1994) Flesh and Stone (London: Faber and Faber).

Simmel, G. (1971) 'The Metropolis and Mental Life', in Levine (ed) On Individuality and Social Forms: Selected Writings (Chicago, IL: University of Chicago Press).

Simmel, G. (1997) 'Sociology of the Senses', in Frisby and Featherstone (eds) Simmel on Culture (London: Sage).

Sorensen, K. (2002). 'Social Shaping on the Move? On the policy relevance of the social shaping of technology perspective', in K. Sorensen and R.
Williams (eds) Shaping Technology, Guiding Policy: Concepts, Spaces and Tools (Cheltenham, UK: Edward Elgar). Sorkin, M. (1992) Variations of a Theme Park (New York: Noonday Press).

Verbeek,P. (2005) What Things Do (Pennsylvania: The Pennsylvania University Press).

Whatmore, S. (2002) Hybrid Geographies (London: Sage).

Williams, R., R. Slack \& J. Stewart (2005) Social Learning in technological innovation - experimenting with information and communication technologies (Cheltenham: Edgar Algar Publishing).

Woodhouse, E. \& J.W. Patton (2004) 'Design by Society: Science and Technology Studies and the Social Shaping of Design', Design Issues, 20 (3):1-12.

Yaneva, A. \& S. Guy (2008) 'Understanding Architecture, Accounting Society', Science Studies 21 (1):3-7.

Zukin, S. (1995) The Cultures of Cities (Oxford: Blackwell).

Monica Degen

Sociology Department

School of Social Sciences

Brunel University

monica.degen@brunel.ac.uk

Gillian Rose

Geography Department

The Open University

Walton Hall

Milton Keynes

g.rose@open.ac.uk

Begum Basdas

Geography Department

The Open University

Walton Hall

Milton Keynes 